\title{
Acute Intravenous Infusion of
} Immunoglobulins Protects Against Myocardial Ischemia-Reperfusion Injury Through Inhibition of Caspase-3

\author{
Waleed Al-Herza,c Fawzi Babiker

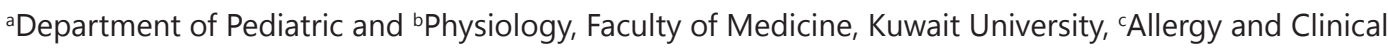 \\ Immunology Unit, Department of Pediatric, Al-Sabah Hospital, Kuwait City, Kuwait
}

\section{Key Words}

Ischemic heart • IVIG $\cdot$ Inflammatory cytokines $•$ Apoptosis $•$ Caspase-3 $\cdot$ Reperfusion

\begin{abstract}
Background/Aims: To investigate the cardioprotective effects of intravenous immunoglobulins (IVIG) in rats subjected to regional myocardial ischemia reperfusion (I/R). Methods: Langendorff-perfused rat hearts were used in this study. Hearts subjected to regional ischemia served as a negative untreated control. The effects of IVIG pre- and post-ischemic treatment on left ventricular function, coronary vascular dynamics and contractility were assessed. IVIG were administered in either a low or high dose. The infarct size was determined using triphenyltetrazolium chloride and through biochemical assays using the measured creatine kinase and lactate dehydrogenase levels. Apoptosis was evaluated by the TUNEL assay, and the caspase-3 expression level was assessed by immunoblotting. The cytokine levels were measured by ELISA. Results: Low and high doses of immunoglobulins administered 2 hours before sacrifice, before the ischemic insult or at reperfusion resulted in a significant improvement in cardiac hemodynamics, coronary vascular dynamics and heart contractility. A significant decrease in the infarct size and cardiac enzymes was also evident compared to those in the control. IVIG administered as an infusion at reperfusion or pre-treatment resulted in a marked decrease in myocyte apoptosis, which was associated with decreased levels of caspase-3 expression in the supernatants of homogenized left ventricles. Infusion of IVIG both pre-ischemia and at reperfusion did not show the same protective effects. Conclusions: This study demonstrates a novel protection to the heart by low and high doses of IVIG given either pre- or post-ischemia.

\section{Introduction}

Despite the advances in their prevention and treatment, ischemic heart diseases (IHDs) result in a remarkable morbidity and mortality [1]. Myocardial reperfusion using either thrombolytic therapy or percutaneous coronary intervention is the only standard therapy 
for patients with acute ST-segment elevation myocardial infarction. However, patients may continue to develop complications during the first year after the infarction [2]. These complications include in-hospital mortality, recurrent myocardial infarction, unstable angina, cardiogenic shock, adverse left ventricular remodeling, or re-hospitalization due to heart failure $[3,4]$. Myocardial ischemia/reperfusion (I/R) injury is the principle cause of such complications [5-8], and several mechanisms were found to be responsible for such injury. These mechanisms include opening of the mitochondrial permeability transition pore (mPTP), intracellular $\mathrm{pH}$ changes, intracellular calcium overload and generation of oxidative stress by reactive oxygen species (ROS) and the inflammation mediated by cytokines and the complement system (via ROS) $[9,10]$. I/R results in notable apoptosis, which is proven to be a cause of I/R injury [11-17]. Therefore, a number of therapeutic interventions to prevent myocardial I/R injury were proposed, but their translation to the clinic did not show the expected outcome $[9,18]$.

The therapeutic intravenous immunoglobulins (IVIG) that are commercially available represent polyvalent immunoglobulins derived from thousands of donors [19]. The IVIG are currently used to treat different autoimmune and inflammatory syndromes [20]. These preparations have anti-inflammatory activity, which is mediated by various mechanisms. These mechanisms include FC-receptor blockade, modulation of the immune activity of both CD4 and CD8 T-lymphocytes, alteration of cytokine profiles, modulation of apoptosis and binding to complement factors and hence prevention of the tissue damage mediated by the complement cascade [20-22]. Pretreatment with IVIG in hepatic I/R injury increased the survival rate, decreased the level of liver enzymes, and showed protection of the liver parenchyma in the experimental animals [23]. Similar protective effects of IVIG against mesenteric I/R were also documented in the clinical research [24]. IVIG were also found to be beneficial when used in a neuronal I/R model, inhibiting toll-like receptor-mediated responses and complement-mediated neuronal cell death [25, 26]. IVIG were also found to protect neurons against ischemic stroke via a pathway involving a reduction of caspase- 3 cleavage and an elevation of the levels of the anti-apoptotic protein Bcl2 in cortical neurons [27].

The aim of this study was to investigate whether IVIG have cardioprotective effects in rats subjected to regional myocardial ischemia when applied before or after the ischemic insult and to understand the possible mechanisms of such protection.

\section{Materials and Methods}

The research protocol was approved by the Kuwait University Health Sciences Center Ethical Committee for animal use. The study was conducted according to the laboratory's animal care guidelines at Kuwait University, Kuwait in accordance with the international standards of animal care. Male Wistar rats weighing 250-300 g were anesthetized with an intraperitoneal injection of sodium pentobarbital (60 $\mathrm{mg} / \mathrm{kg}$ ) with the anticoagulant heparin (1000 U/kg body weight) through the femoral vein. The heart was attached to a modified Langendorff setup for the perfused rat heart, as described previously [28]. Briefly, the hearts were retrogradely perfused with freshly prepared Krebs-Hensleit solution. The buffer was gassed with a mixture of oxygen (95\%) and $\mathrm{CO}_{2}(5 \%), \mathrm{pH} 7.35-7.45$, at a temperature of $37.0 \pm 0.5^{\circ} \mathrm{C}$. The perfusion pressure (PP) was kept constant at $50 \mathrm{~mm} \mathrm{Hg}$ throughout the experimental procedure in all of our protocols. PP was measured in a branch of the aortic cannula using a Statham pressure transducer (P23 Db). Constant PP was ensured electronically by means of a perfusion assembly (Module PPCM type 671, Hugo Sachs Electronik, Germany). This system permits an accurate adjustment of PP between 5 and $150 \mathrm{~mm} \mathrm{Hg}$ with an accuracy of $\pm 1 \mathrm{~mm} \mathrm{Hg}$. The temperature of the perfusion medium was maintained at $37^{\circ} \mathrm{C}$ by circulating, temperature-controlled water (RMS Lauda, Germany and Techne Circulator, USA). This temperature was the control perfusion temperature for all protocols of this study. The myocardial temperature was monitored by a needle thermistor probe (Thermlert TH-5, Physitemp, USA) inserted at the apex of the heart for each protocol of the study. 


\section{Cellular Physiology Cell Physiol Biochem 2017;42:2295-2306 \begin{tabular}{cc|c|c|} 
DOI: 10.1159/000480002 & C 2017 The Author(s). Published by S. Karger AG, Basel \\
www.karger.com/cpb
\end{tabular}

The heart was instrumented with pacing electrodes on the right atrial (RA) appendage. The left descending coronary artery was encircled with a snare at approximately $0.5 \mathrm{~cm}$ below the atrioventricular groove, and a small rigid plastic tube was positioned between the heart and the snare to ensure complete occlusion of the coronary artery. The aorta was cannulated, allowing retrograde perfusion of the heart with a preload of $6 \mathrm{~mm} \mathrm{Hg}$. The preload was kept constant under basal-control conditions.

\section{Study protocol}

The present study investigated the role of pre- and post-treatments with immunoglobulins (Gamunex ${ }^{\circledR}-\mathrm{C}$; Grifols Therapeutics Inc, NC, USA) or the combination thereof on the protection of the heart against I/R injury (Fig. 1).

For the pre-treatment protocol, the subjects were subdivided into 4 groups. In group $\mathrm{A}$, the sham hearts $(\mathrm{n}=6)$ were cannulated, and a thread was passed below the coronary artery with no further treatment. In group B, control hearts (n = 6) were subjected to I/R without any further treatment. In group C, either low dose IVIG (IgL) $(0.6 \mathrm{~g} / \mathrm{kg})$ or high dose IVIG (IgH) $(1 \mathrm{~g} / \mathrm{kg})(\mathrm{n}=6$ each) was infused in the buffer following the stabilization period at $15 \mathrm{~min}$ before the index ischemia. In group $D$, the rats $(n=6$ each) were intravenously infused with either IgL or IgH 2 hrs before sacrifice and heart isolation (Fig. 1).

For the post-treatment experiments, the hearts of untreated rats were isolated. The hearts in treatment group $\mathrm{E}$ were treated with either IgL or IgH $(\mathrm{n}=6 \mathrm{each}) 5 \mathrm{~min}$ before reperfusion, and the treatment was continued for 10 minutes after the start of reperfusion. The hearts in the combined treatment group F were treated with either IgL or IgH in the buffer $15 \mathrm{~min}$ before ischemia and $5 \mathrm{~min}$ before reperfusion, and the treatment was continued for 10 minutes thereafter $(n=6$ each). In all hearts, the ischemia was produced by $30 \mathrm{~min}$ of coronary artery occlusion (CAO), followed by $30 \mathrm{~min}$ of reperfusion.

\section{Hemodynamic evaluations}

Coronary flow (CF) was measured continuously by an electromagnetic flow probe attached to the inflow of the aortic cannula. The probe was attached to a flow meter, which was interfaced to a personal computer. The CF in $\mathrm{mL} / \mathrm{min}$ was continuously monitored by timed collection of the coronary effluent, and computations were performed. The coronary vascular resistance (CVR) was computed every 10 seconds along with the hemodynamic data by an on-line data acquisition program (Isoheart software V 1.524-S, Hugo-Sachs Electronik, Germany). The left ventricular developed pressure (DPmax) and left ventricular end diastolic pressure (LVEDP) were measured by placing and securing a water-filled latex balloon in the left ventricular cavity. The balloon was attached to a pressure transducer, and the DC-Bridge amplifier (DCBA) of the pressure module (DC-BA type 660, Hugo-Sachs Electronik, Germany) interfaced to a personal computer for on-line monitoring of the left ventricular pressure and its derivatives. The left ventricular DPmax was derived from the online acquisition of left ventricular systolic pressure (LVSP) by the Max-Min module. This module converts the output from the DC-BA to DPmax by subtracting LVEDP from the maximal LVSP. 


\section{Cellular Physiology Cell Physiol Biochem 2017;42:2295-2306 \begin{tabular}{ll|l} 
DOI: 10.1159/000480002 & $\begin{array}{l}\text { @ 2017 The Author(s). Published by S. Karger AG, Basel } \\
\text { www.karger.com/cpb }\end{array}$ \\
and Biochemistry Published online: August 17, 2017 &
\end{tabular}}

Al-Herz: IVIG Protection Against Cardiac I/R

\section{Cardiac damage assessment via infarct size and cardiac enzymes}

Although the risk area can be perfectly evaluated using real-time myocardial contrast echocardiography (MCE) [29], this study used the triphenyltetrazolium chloride (TTC) method and cardiac enzymes level, which fit better in our ex vivo study. Infarct size was determined by the TTC method. Hearts were collected after $30 \mathrm{~min}$ of reperfusion and stored overnight at $-20^{\circ} \mathrm{C}$. The next day, the hearts were cut into 4-5 pieces from apex to base, incubated in TTC (1\%) solution in isotonic $\mathrm{pH} 7.4$ phosphate buffer and then fixed with formaldehyde (4\%). Images were taken using a Nikon camera. The pale red, unstained areas of every slice were marked manually on the image, and the corresponding areas and were quantified using Leica ImageJ (ImageJ, Wayne Rasb and National Institute of Health, USA). The ratio of infarct size to LV area was calculated and expressed as a percentage for every heart. Cardiomyocyte injury was evaluated by measuring the cardiac enzyme, creatine kinase (CK) and lactate dehydrogenase (LDH) levels in the coronary effluent during the reperfusion period, as described previously [30].

Assessment of apoptosis: terminal deoxynucleotidyl transferase mediated UTP nick end labeling (TUNEL assay)

Three-micrometer thick paraffin sections were de-waxed by submersion in xylene, rehydrated by passing through descending grades of alcohol $(100-70 \%$ alcohol), washed with distilled water and PBS, immersed in antigen retrieval solution (sodium citrate buffer: a mixer of $13.5 \mathrm{ml}$ of solution A (21 g citric acid monohydrate in $1 \mathrm{~L}$ distilled water $)+61.5 \mathrm{ml}$ of solution $\mathrm{B}(29.4 \mathrm{~g}$ sodium citrate dehydrate in $1 \mathrm{~L}$ distilled water) with distilled water for the remained of the $750 \mathrm{ml}$ volume) for $5 \mathrm{~min}$ in a microwave oven at medium power. Tissue sections were brought to room temperature, kept in PBS for $5 \mathrm{~min}$, in triton X $0.1 \%$ in PBS, Triton-Sigma-Aldrich, 234729) for 8 min and washed twice with PBS. Fifty microliters of TUNEL reaction mixture (50 $\mu \mathrm{l}$ of enzyme solution (terminal deoxynucleotidyl transferase from calf thymus (EC 2.7.7.31) in storage buffer) and $450 \mu \mathrm{l}$ of labeling solution (nucleotide in reaction buffer)) was added to the section until the whole tissue was covered. The negative control section was covered with only $50 \mu$ of labeling solution. The slides were incubated in humidified chamber for 1 hour at $37^{\circ} \mathrm{C}$ and rinsed thrice in PBS. Next, freshly prepared DAPI (4' 6-diamidino-2-phenylindole, 1:4000, Sigma Chemicals, D9542) was added to the tissue section for $1 \mathrm{~min}$, and the sections were mounted in Vectashield (Vector Laboratories; CA-94010). The edges of the cover slips were sealed with nail polish. The slides were examined using a confocal microscope, and selected areas were photographed. Ten fields/heart were examined, the nuclei of TUNEL-positive myocytes were counted, and the mean values were calculated. An In situ Cell Death Detection Fluorescein kit (Roche) was used for this purpose.

\section{Immunoblotting}

Left ventricles ( $n=4$ per group) were homogenized in ice-cold lysis buffer, and the homogenate

was centrifuged at $4000 \mathrm{rpm}$ for $10 \mathrm{~min}$. The supernatant was collected, the protein content was measured, and the samples were aliquoted and stored at $-80^{\circ} \mathrm{C}$ for further analysis. The expression of the evaluated proteins was determined as described previously [31]. Equal loading was checked by stripping the membrane and reprobing with actin antibodies. The total caspase-3 level was determined using monoclonal antibodies (Cell Signaling Technology, Inc). Detection was performed using enhanced chemiluminescence after incubation with a suitable secondary antibody conjugated to horseradish peroxidase (ECL; Cell Signaling Technology). Densitometric analysis was performed using Quantity One software (BioRad).

\section{Pro-inflammatory cytokine testing}

Left ventricular tissues were homogenized in ice-cold lysis buffer, and the homogenate was centrifuged at $4000 \mathrm{rpm}$ for $10 \mathrm{~min}$. The supernatant was removed, and the protein content was measured. Dilution was performed as required by manufacturers' guidelines. The expression of pro-inflammatory cytokines [TNF-alpha (TNF- $\alpha$ ), interleukin 1 (IL-1) and interleukin 6 (IL-6)] were determined by ELISA. The detection procedures for each of the proteins were performed according to the guidelines of the manufacturers of the respective commercial kits. The titers of IL- 1 , IL- 6 and TNF- $\alpha$ in cardiac muscle samples were used. The rat IL-1, IL-6 and TNF- $\alpha$ kits were obtained from Biosource International, USA.

Sample storage

All samples were immediately frozen in liquid nitrogen and subsequently stored at $-80^{\circ} \mathrm{C}$. 
Fig. 2. Left ventricle function (DPmax and LVEDP) and coronary-vascular-dynamics (CF and CVR) post-ischemic recovery after IVIG treatment protocols. The data was computed at 30 min reperfusion and expressed as mean \pm SEM. DPmax: maximum developed pressure; LVEDP: left ventricular end diastolic pressure; CF: coronary flow; CVR: coronary vascular resistance; Ctr: control; IgL: low dose immunoglobulin $(0.6 \mathrm{~g} / \mathrm{kg})$; IgH: high dose immunoglobulin (1g/kg); R: reperfusion; IV: intravenously; P: pretreatment (15 min before ischemia) A: IVIG pre-treatment protocol infusion either in the buffer during the stabilization period $15 \mathrm{~min}$ before the index ischemia or infusion intravenously within 2 hrs before sacrificing the rats and heart isolation showed cardioprotective effects by means of $\mathrm{LV}$ function and coronary-vasculardynamics. ${ }^{*} \mathrm{P}<0.01$ compared to respective controls, ${ }^{* *} \mathrm{P}<0.01$ compared to sham and ${ }^{\dagger} \mathrm{P}<0.001$ compared to ischemic period. B: IVIG infusion at reperfusion (both IgL and IgH) showed cardioprotective effects by means of LV function and coronary-vasculardynamics. ${ }^{*} \mathrm{P}<0.05$ compared to respective controls, ${ }^{* *} \mathrm{P}<0.01$ compared to sham and. ${ }^{\dagger} \mathrm{P}<0.01$ compared to ischemic period for IVIG treatments. C: Combined IVIG (both IgL and IgH) pre- and post-treatment infusion showed no cardio-protective effects by means of LV function and coronary-vascular-dynamics. This is in contrast to either pre- or post-treatment given alone. The pre-treatment protocol shown was done using IVIG infusion in the buffer. ${ }^{*} \mathrm{P}<0.01$ compared to respective controls and ${ }^{\dagger} \mathrm{P}<0.01$ compared to ischemic period for IVIG at reperfusion (IgH/R and IgL/R).

\section{Statistical analysis}

All data are presented as the mean \pm SE. One-way analysis of variance (ANOVA) for repeated measures within each group and between groups was performed on absolute values, even when presented as \% of baseline. Only in cases when this analysis showed a significant difference, post hoc analysis was used for
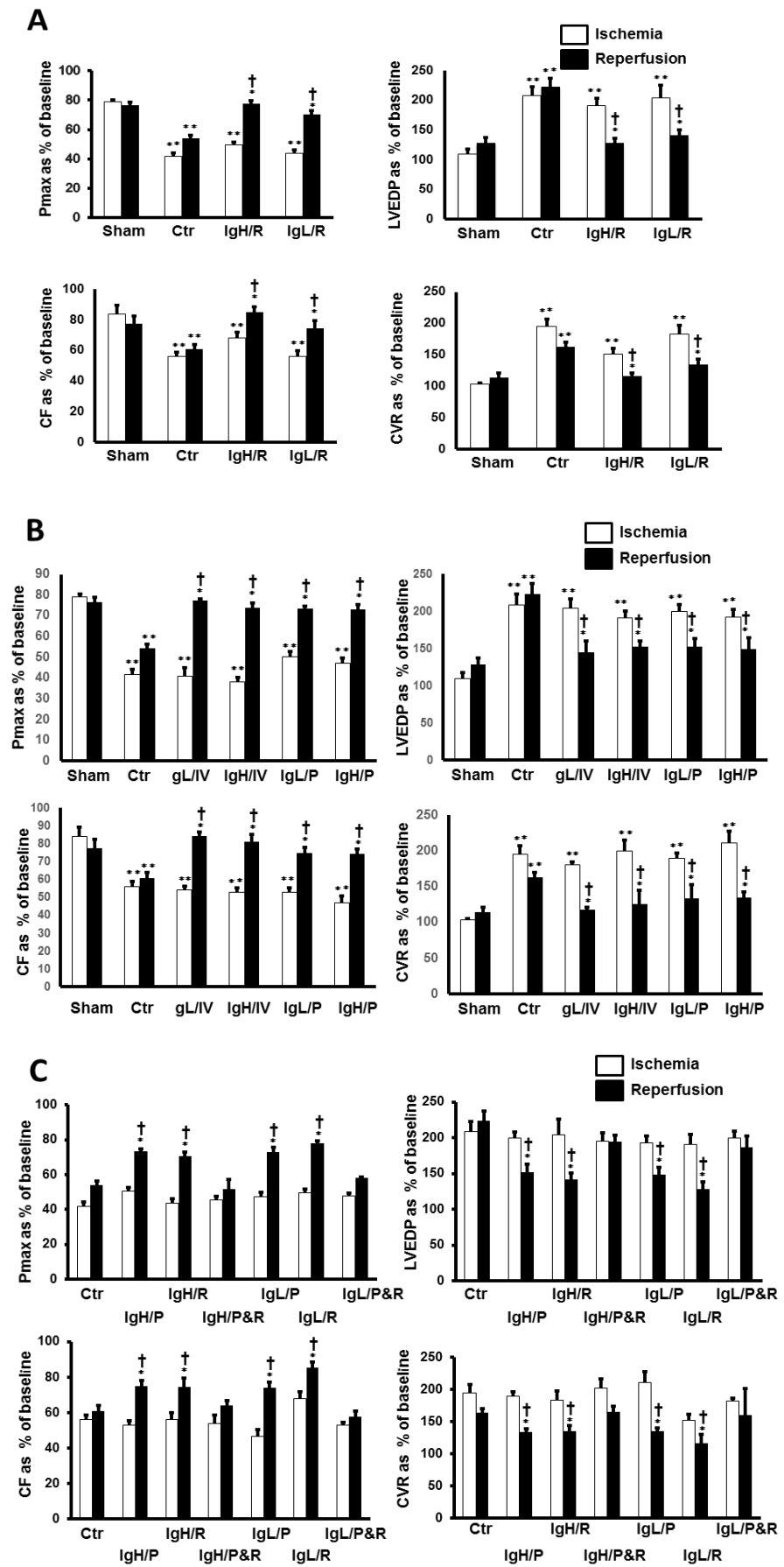

KARGER 
further comparison. $\mathrm{P}<0.05$ was considered statistically significant.

\section{Results}

Hemodynamic effects of IVIG

The heart hemodynamics, contractility and coronary vascular dynamics changed in sham animals; however, the changes in these parameters were not statistically significant throughout the protocol period. Induction of ischemia resulted in a significant $(\mathrm{P}<0.01)$ worsening in the heart and coronary vascular dynamics compared to those in the sham hearts. Interestingly, both low and high doses of IVIG treatment given 2 hours before animal sacrifice or preischemic insult significantly improved the left ventricular function by increasing DPmax and decreasing LVEDP compared to those of the respective controls $(\mathrm{P}<0.05)$ (Fig. 2A). Coronary vascular dynamics were also positively affected, as shown by the significant increase in $\mathrm{CF}$ and decrease in CVR compared to those of the respective controls $(\mathrm{P}<0.05)$ (Fig. 2A). Compared to the respective controls, IVIG treatment normalized the myocardial contractility, as assessed by $+\mathrm{dP} / \mathrm{dt}$ and $-\mathrm{dP} /$ dt $(\mathrm{P}<0.05)$ (Table 1). Similar effects were achieved when IVIG were administered at reperfusion (Fig. 2B and Table
Table 1. Effects of IVIG treatment protocols on post-ischemic recovery of left ventricular contractility $(+\mathrm{dP} / \mathrm{dt}$ and $-\mathrm{dP} / \mathrm{dt})$. $\mid$ Mean $\pm \mathrm{SE},{ }^{*} \mathrm{P}<0.01$ and ${ }^{* *} \mathrm{P}<0.05$ compared to respective controls, $\mathrm{t} \mathrm{P}<$ 0.001 and $\mathrm{H} \mathrm{P}<0.01$ compared to ischemic period for IVIG, IgL: low dose immunoglobulin $(0.6 \mathrm{~g} / \mathrm{kg})$; IgH: high dose immunoglobulin (1g/kg); R: reperfusion; IV: intravenously; P: pretreatment (15 min before ischemia)

\begin{tabular}{|c|c|c|c|c|}
\hline \multirow[b]{2}{*}{ Treatment } & \multicolumn{2}{|c|}{$+\mathrm{dP} / \mathrm{dt} \mathbb{T}$} & \multicolumn{2}{|c|}{$-\mathrm{dP} / \mathrm{dt} \mathbb{T}$} \\
\hline & Ischemia & Reperfusion & Ischemia & Reperfusion \\
\hline Control & $48.48 \pm 2.46$ & $62.38 \pm 2.59$ & $50.88 \pm 2.45$ & $60.63 \pm 2.23$ \\
\hline IgL/R & $50.65 \pm 3.75$ & $71.52 \pm 3.22 * t$ & $50.59 \pm 3.57$ & $72.86 \pm 4.13 * t$ \\
\hline $\mathrm{IgH} / \mathrm{R}$ & $60.13 \pm 2.74$ & $79.05 \pm 2.83 * t$ & $60.69 \pm 3.23$ & $74.08 \pm 3.47 * t$ \\
\hline $\operatorname{IgL} / \mathrm{P}$ & $49.26 \pm 2.77$ & $73.65 \pm 4.13^{* *} \mathrm{H}$ & $49.20 \pm 1.42$ & $69.53 \pm 2.56^{* *} \mathrm{H}$ \\
\hline $\mathrm{IgH} / \mathrm{P}$ & $46.79 \pm 1.72$ & $69.50 \pm 1.06 * * \mathrm{H}$ & $41.68 \pm 1.12$ & $68.63 \pm 2.32 * * \mathrm{H}$ \\
\hline IgL/IV & $49.98 \pm 2.21$ & $77.27 \pm 2.45^{* *} \mathrm{H}$ & $49.20 \pm 1.42$ & $77.19 \pm 2.81^{* *} \mathrm{H}$ \\
\hline $\mathrm{IgH} / \mathrm{IV}$ & $49.80 \pm 1.41$ & $75.12 \pm 3.29 * *$ & $49.73 \pm 1.80$ & $71.31 \pm 2.51 * * H$ \\
\hline IgL/P\&R & $51.51 \pm 1.40$ & $55.53 \pm 2.33$ & $47.74 \pm 1.58$ & $54.53 \pm 2.42$ \\
\hline $\mathrm{IgH} / \mathrm{P} \& \mathrm{R}$ & $49.68 \pm 2.67$ & $57.11 \pm 2.53$ & $53.61 \pm 2.39$ & $58.45 \pm 2.03$ \\
\hline
\end{tabular}

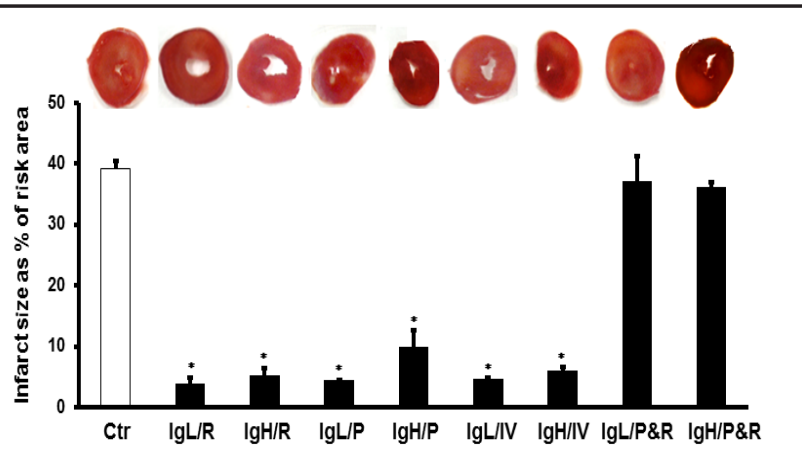

Fig. 3. Infarct size after IVIG treatment protocols. IVIG as pretreatment or at reperfusion decreased infarct size while combined pre- and post-treatment with IVIG showed no differences in the infarct size compared to the control group. Top: representative 2,3,5-triphenyl-2H-tetrazolium chloride-stained heart slices from the apex to base. Bottom, measured infarct size, normalized to the LV area, in isolated rat hearts at the end of reperfusion. Ctr: control; IgL: low dose immunoglobulin $(0.6 \mathrm{~g} / \mathrm{kg})$; IgH: high dose immunoglobulin $(1 \mathrm{~g} / \mathrm{kg}) ; \mathrm{R}$ : reperfusion; IV: intravenously; P: pretreatment (15 min before ischemia). ${ }^{*} \mathrm{P}<0.001$ compared to respective controls.

1). Surprisingly, the combination of immunoglobulin treatments pre- and post-ischemia showed no cardioprotective effects (Fig. 2C and Table 1). The recovery values shown in all hearts and cardiovascular parameters were comparable to the sham group values (Fig. 2).

\section{Infarct size}

Immunoglobulin (low or high dose) infusion at reperfusion caused a significant reduction in infarct size compared to that of the respective controls ( $<<0.001)$ (Fig 3). Similar effects were found when IVIG were given during the pre-ischemia treatment protocols with either dose in the buffer $15 \mathrm{~min}$ before the index ischemia or when IVIG were infused intravenously 
2 hrs before the rat sacrifice and heart isolation. However, the combined preand post-ischemia treatments with IVIG showed no improvement in the infarct size compared to that of the control group.

\section{Cardiac enzymes}

For both doses of IVIG, administration post-treatment at reperfusion or pretreatment either infused in the buffer $15 \mathrm{~min}$ before the index ischemia or via intravenous injection $2 \mathrm{hrs}$ before the rat sacrifice resulted in a significant decrease in the cardiac enzymes LDH and CK compared to those of the respective controls. This effect was completely abrogated when IVIG were administered both pre- and post-treatment (Table 2).

IVIG effects on cardiomyocyte survival

IVIG administration at reperfusion or pre-ischemic treatment either dosed in the buffer following the stabilization period 15 min before the index ischemia or infused intravenously 2 hrs before sacrificing the rats and heart isolation either in low or high doses resulted in a marked decrease in myocytes apoptosis $(\mathrm{P}<0.01)$ (Fig. 4). This effect was smaller when IVIG were administered both pre- and post-ischemic treatment. These results were confirmed by the caspase-3 expression levels (Fig. 5).

\section{Pro-inflammatory cytokines}

All IVIG treatment protocols resulted in a significant increase in the L- 1 and IL-6 levels in the cardiac muscle samples. However, the TNF- $\alpha$ expression level did not increase (Fig. 6).

Fig. 4. IVIG effects on myocytes apoptosis. IVIG resulted in a decreased myocytes apoptosis. Top: Images representing cell staining for apoptosis, control (A), IgL/R (B), $\operatorname{IgH} / \mathrm{R}(\mathrm{C}), \operatorname{IgL} / \mathrm{P}(\mathrm{D}), \operatorname{IgH} / \mathrm{P}(\mathrm{E})$, $\operatorname{IgL} / \operatorname{IV}(\mathrm{F}), \operatorname{IgH} / \mathrm{IV}(\mathrm{G}), \operatorname{IgL} / \mathrm{P} \& \mathrm{R}(\mathrm{H})$ and IgH/P\&R (I). Bottom: graphic representation of apoptotic cells as a percentage of total heart cells. ${ }^{*} \mathrm{P}<0.01$ compared to control. Ctr: control; IgL: low dose immunoglobulin $(0.6 \mathrm{~g} / \mathrm{kg})$; IgH: high dose immunoglobulin $(1 \mathrm{~g} /$ $\mathrm{kg);} \mathrm{R:} \mathrm{reperfusion;} \mathrm{IV:} \mathrm{intravenously;}$ P: pretreatment (15 min before ischemia).
Table 2. Effects of various IVIG treatments on heart enzymes levels, * Mean \pm SE, ๆ P-value compared to respective controls, IgL: low dose immunoglobulin $(0.6 \mathrm{~g} / \mathrm{kg})$; IgH: high dose immunoglobulin $(1 \mathrm{~g} / \mathrm{kg})$; R: reperfusion; IV: intravenously; P: pretreatment (15 min before ischemia)

\begin{tabular}{lcccc}
\hline Treatment & ${ }^{*} \mathrm{CK}(\mathrm{IU} / \mathrm{L})$ & I P value & ${ }^{*} \mathrm{LDH}(\mathrm{IU} / \mathrm{L})$ & $\mathrm{P}$ value \\
\hline Control & $13.5 \pm 0.5$ & - & $7.6 \pm 0.4$ & - \\
IgL/R & $8.5 \pm 0.7$ & 0.006 & $4.2 \pm 1.0$ & 0.04 \\
IgH/R & $7.4 \pm 1.3$ & 0.01 & $4.3 \pm 0.8$ & 0.03 \\
IgL/P & $7.9 \pm 0.9$ & 0.006 & $3.5 \pm 0.6$ & 0.004 \\
IgH/P & $8.1 \pm 0.8$ & 0.001 & $3.4 \pm 0.6$ & 0.005 \\
IgL/IV & $7.4 \pm 1.2$ & 0.01 & $2.7 \pm 1.1$ & 0.01 \\
IgH/IV & $5.7 \pm 0.9$ & 0.002 & $5.0 \pm 0.3$ & 0.007 \\
IgL/P\&R & $11.1 \pm 1.6$ & 0.30 & $9.1 \pm 1.0$ & 0.25 \\
IgH/P\&R & $10.7 \pm 0.8$ & 0.10 & $8.7 \pm 0.3$ & 0.11 \\
\hline
\end{tabular}

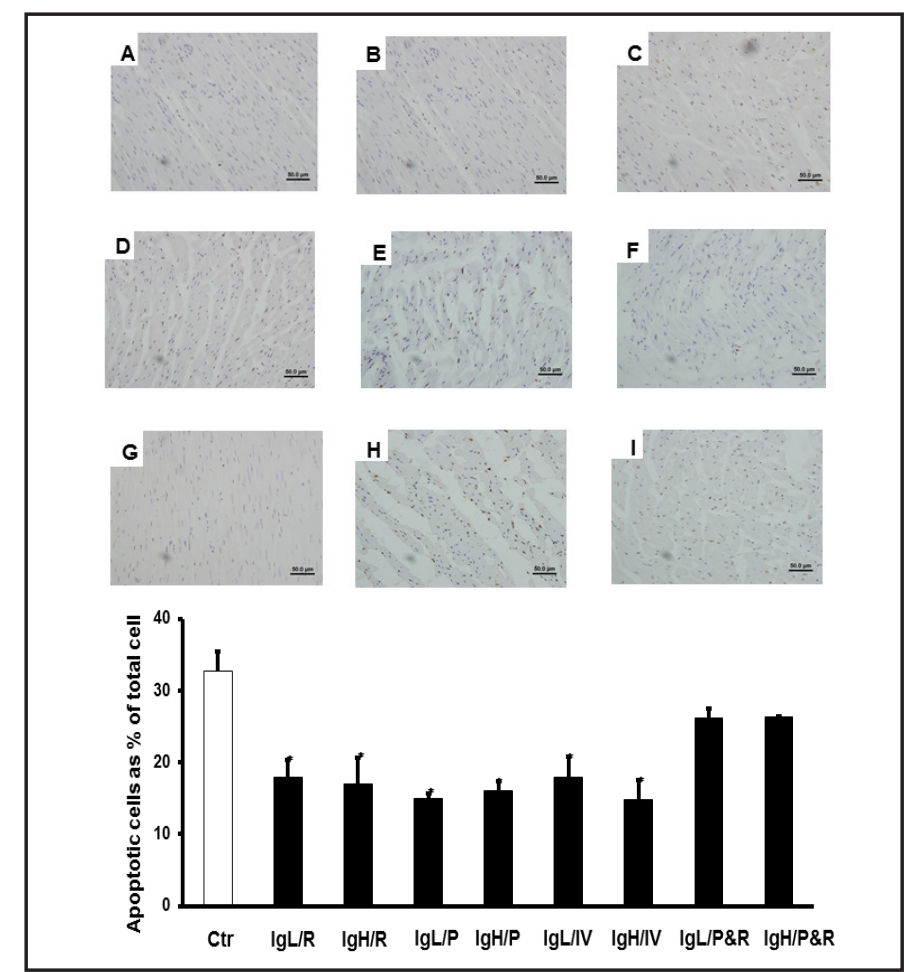


Fig. 5. IVIG effect on caspase-3 expression in the supernatants of homogenized left ventricles by immunoblotting. IVIG as pre-treatment or at reperfusion decreased levels of caspase-3 expression while combined preand post-treatment with IVIG showed no differences in the levels of caspase- 3 expression compared to the control

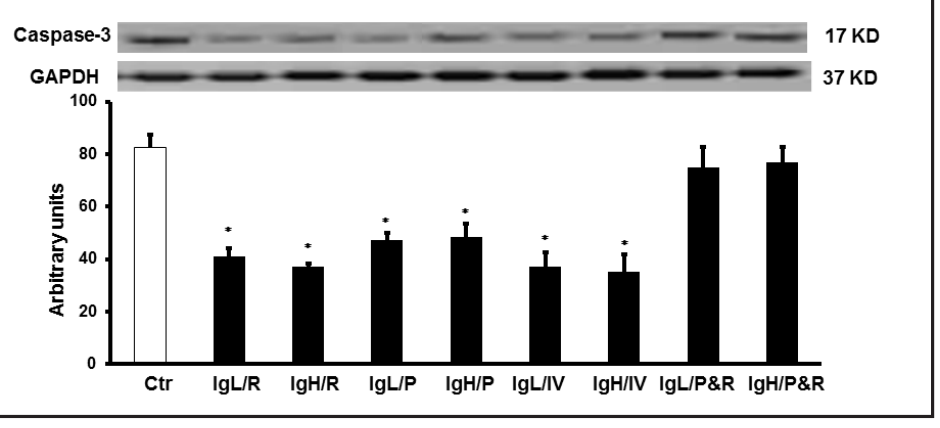
group. ${ }^{*} \mathrm{P}<0.01$ compared to control. Ctr: control; IgL: low dose immunoglobulin (0.6g/kg); IgH: high dose immunoglobulin (1g/kg); R: reperfusion; IV: intravenously; P: pretreatment (15 min before ischemia).

\section{Discussion}

In the current study, IVIG showed significant cardioprotective effects in rat hearts subjected to regional myocardial ischemia when applied before or after the ischemic insult; the effects were assessed using hemodynamic evaluation, infarct size and cardiac enzymes.

Several therapeutic interventions were reported as protective procedures against myocardial I/R injury. However, it is too soon for some of these procedures to be used in clinical practice [32-35]. Other procedures showed disappointing results when were translated to the clinic [36-38]. Ischemic preconditioning (repetitive ischemic episodes before the insult) was proposed in attempt to decrease I/R injury [39]. Although this method showed considerable heart protection [28, 40,41], the likelihood of its use in clinical application is rather limited because of the unexpectedness of most ischemic events. More applicable in clinical practice is ischemic postconditioning (repetitive ischemia at the onset of reperfusion) [42]. Indeed, this method showed pronounced heart protection, but its application in the clinic is still questionable because of the potential damage to coronary blood vessels. Given the safety profile of IVIG and its being protective shortly before reperfusion, IVIG seem to be an attractive possibility for patients undergoing reperfusion post-myocardial infarction. In a recent study, Gullestad et al. administered IVIG as induction therapy to acute myocardial infarction patients suffering a depressed left ventricular ejection fraction (LVEF) after they were treated by percutaneous coronary intervention and thereafter as monthly infusions for 26 weeks [43]. Compared to placebo, IVIG did not improve myocardial function, left ventricle remodeling or infarct size during follow-up. A major limitation of this study is that the study only included a small number of patients who had depressed left ventricle function. The study also evaluated few markers as primary endpoints. Many other parameters other than LVEF, such as duration of stay in intensive care units and rate of complications (e.g., arrhythmias, cardiogenic shock, recurrent myocardial infarction, unstable angina, hospitalization and mortality), should be considered when evaluating the effects of this regimen in future clinical trials. Moreover, the cumulative IVIG dose during the induction therapy was $2 \mathrm{~g} / \mathrm{kg}$, which is relatively high and could be responsible for the absence of the protective effects; this absence was similar to our study, where no cardioprotective effects were found in the combined IgL and IgH treatment group. Additionally, we are not sure whether the IVIG treatment in the Gullestad study was provided before or a few hours after reperfusion, whereas in our study, IVIG were beneficial when administered a few minutes before reperfusion.

Modulation of apoptosis and cell death is a well-known anti-inflammatory effect of IVIG [19]. These effects result from several mechanisms, such as suppression of NLRP1 and NLRP3 inflammasome activity, anti-Fas effects, inhibition of the caspase-3, caspase-8 and caspase- 9 cascades, modulation of BCR signaling and inhibition of complement-mediated apoptosis [26, 44-47]. Furthermore, other immunomodulatory effects of IVIG may have

\section{KARGER}


Fig. 6. Pro-inflammatory cytokines levels in the cardiac muscle samples after IVIG infusion compared to the control group. IVIG increased IL-1 (A) and IL-6 (B) while it did not affect TNF- $\alpha$ levels. Ctr: control; IgL: low dose immunoglobulin (0.6g/ $\mathrm{kg}$ ); IgH: high dose immunoglobulin (1g/ $\mathrm{kg}$ ); R: reperfusion; IV: intravenously; P: pretreatment (15 min before ischemia).

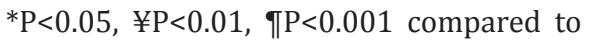
the respective control.

played a role in this cardioprotective effect, so further studies are needed to better understand these mechanisms. However, more studies are also needed to understand the lack of protection demonstrated by the pre- and post-IVIG combination. We anticipate that this lack of protection could be due to the high IVIG dose. Combining two protocols of IVIG before ischemia and at reperfusion might have resulted in a dose higher than the threshold required for protection and may activate specific molecules that offset the IVIG-induced protection. This result could also be related to the duration of IVIG infusion, as the duration of the protective procedure has been proven to be essential for the outcome. Longer episodes were previously proven to offset the protective effect in some studies [48]. Pharmacological interventions that span the ischemic period were also found to impact the ischemic event and block the expected protection [49]. This scenario might be applicable in the combination of preand post-ischemic IVIG treatments. Further studies are required to
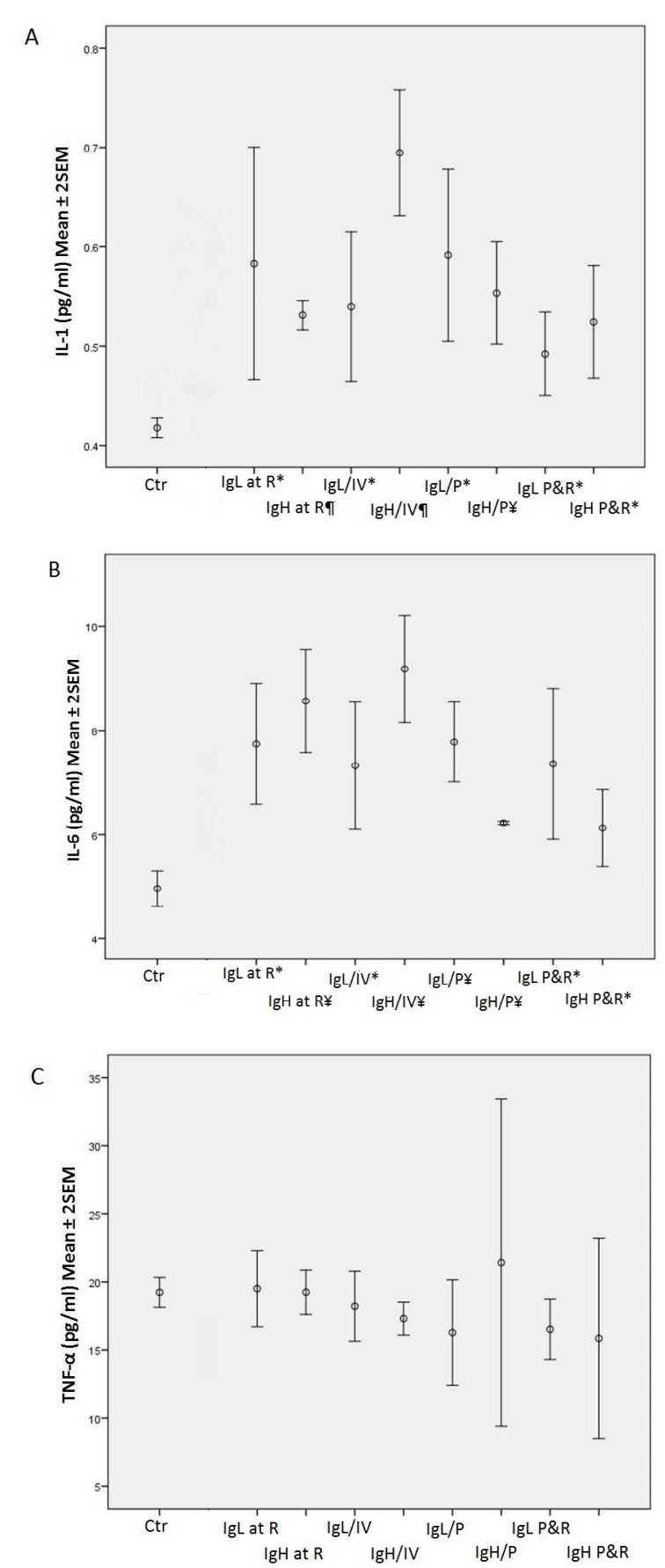

resolve this controversy before testing this regimen in the clinic.

Decreasing the levels of pro-inflammatory cytokines was found to be crucial for the protection against tissue damage induced by cardiac I/R [40, 50, 51]. Interestingly, the IVIG treatment in the current study not only exerted protective effects against I/R injury but also resulted in an increase in IL- 1 and IL- 6 levels but not TNF- $\alpha$ levels. These findings are in line with previous studies in which IVIG infusion resulted in a significant increase in the proinflammatory cytokine levels [52-54]. The presence of protective effects due to IVIG infusion in the presence of increased pro-inflammatory cytokine levels is in contrast to the previous findings and requires further investigations. IVIG may protect against I/R injury through pathways that bypass the potential harmful effects of these pro-inflammatory cytokines. 


\section{Cellular Physiology Cell Physiol Biochem 2017;42:2295-2306 \begin{tabular}{l|l|l}
\hline and BOI: 10.1159/000480002 & $\begin{array}{l}\text { C) } 2017 \text { The Author(s). Published by S. Karger AG, Basel } \\
\text { www.karger.com/cpb }\end{array}$ \\
\hline
\end{tabular}}

Al-Herz: IVIG Protection Against Cardiac I/R

\section{Conclusion}

Both low and high doses of IVIG were shown to have protective effects against I/R injury of the heart when administered before ischemia or at reperfusion, and the effect was similar to that attained by classical postconditioning methods. Because they are protective shortly before reperfusion, IVIG may be considered a safe and easy treatment that can be used in clinical practice.

\section{Acknowledgements}

We would like to thank Kuwait University Research Administration for their support in granting the project (MK01/13) and facilitating research implementation.

\section{Disclosure Statement}

WA received travel grants to attend medical conferences from Baxter, Grifols and CSL Behring.

\section{References}

1 Hausenloy DJ, Yellon DM: Preconditioning and postconditioning: underlying mechanisms and clinical application. Atherosclerosis 2009;204:334-341.

-2 Cung TT, Morel O, Cayla G, Rioufol G, Garcia-Dorado D, Angoulvant D, Bonnefoy-Cudraz E, Guérin P, Elbaz M, Delarche N, Coste P, Vanzetto G, Metge M, Aupetit JF, Jouve B, Motreff P, Tron C, Labeque JN, Steg PG, Cottin Y, Range G, Clerc J, Claeys MJ, Coussement P, Prunier F, Moulin F, Roth O, Belle L, Dubois P, Barragan P, Gilard M, Piot C, Colin P, De Poli F, Morice MC, Ider O, Dubois-Randé JL, Unterseeh T, Le Breton H, Béard T, Blanchard D, Grollier G, Malquarti V, Staat P, Sudre A, Elmer E, Hansson MJ, Bergerot C, Boussaha I, Jossan C, Derumeaux G, Mewton N, Ovize M: Cyclosporine before PCI in Patients with Acute Myocardial Infarction. N Engl J Med 2015;373:1021-1031

3 Piper HM, Garcia-Dorado D, Ovize M: A fresh look at reperfusion injury. Cardiovasc Res 1998;38:291-300.

4 Yellon DM, Hausenloy DJ: Myocardial reperfusion injury. N Engl J Med 2007;357: 1121-1135.

5 Bishopric NH, Andreka P, Slepak T, Webster KA: Molecular mechanisms of apoptosis in the cardiac myocyte. Curr Opin Pharmacol 2001;1:141-150.

6 Hajnoczky G, Csordas G, Madesh M, Pacher P: Control of apoptosis by IP(3) and ryanodine receptor driven calcium signals. Cell Calcium 2000;28:349-363.

7 Halestrap AP, Clarke SJ, Javadov SA: Mitochondrial permeability transition pore opening during myocardial reperfusion--a target for cardioprotection. Cardiovasc Res 2004; 61:372-385.

8 Hausenloy DJ, Yellon DM: The mitochondrial permeability transition pore: its fundamental role in mediating cell death during ischaemia and reperfusion. J Mol Cell Cardiol 2003;35:339-341.

-9 Fröhlich GM, Meier P, White SK, Yellon DM, Hausenloy DJ: Myocardial reperfusion injury: looking beyond primary PCI. Eur Heart J 2013;34:1714-1722.

10 Arumugam TV, Okun E, Tang SC, Thundyil J, Taylor SM, Woodruff TM: Toll-like receptors in ischemiareperfusion injury. Shock 2009;32:4-16.

11 Kajstura J, Cheng W, Reiss K, Clark WA, Sonnenblick EH, Krajewski S, Reed JC, Olivetti G, Anversa P: Apoptotic and necrotic myocyte cell deaths are independent contributing variables of infarct size in rats. Lab Invest 1996;74:86-107.

12 Vanlangenakker N, Berghe TV, Krysko DV, Festjens N, Vandenabeele P: Molecular mechanisms and pathophysiology of necrotic cell death. Curr Mol Med 2008;8:207-220.

13 Arumugam TV, Selvaraj PK, Woodruff TM, Mattson MP: Targeting ischemic brain injury with intravenous immunoglobulin. Expert Opin Ther Targets 2008;12:19-29.

-14 Arumugam TV, Chan SL, Jo DG, Yilmaz G, Tang SC, Cheng A, Gleichmann M, Okun E, Dixit VD, Chigurupati S, Mughal MR, Ouyang X, Miele L, Magnus T, Poosala S, Granger DN, Mattson MP: Gamma secretaseYmediated Notch signaling worsens brain damage and functional outcome in ischemic stroke. Nat Med 2006;12:621623. 


\section{Cellular Physiology Cell Physiol Biochem 2017;42:2295-2306 \begin{tabular}{l|l|l} 
and Biochemistry Published onlIne: August 17, 2017 & $\begin{array}{l}\text { C) } 2017 \text { The Author(s). Published by S. Karger AG, Basel } \\
\text { www.karger.com/cpb }\end{array}$ \\
\hline
\end{tabular}}

Al-Herz: IVIG Protection Against Cardiac I/R

15 Liu P, Xu B, Cavalieri TA, Hock CE: Pifithrin-alpha attenuates p53-mediated apoptosis and improves cardiac function in response to myocardial ischemia/reperfusion in aged rats. Shock 2006;26:608-614.

-16 Nakano H, Nakajima A, Sakon-Komazawa S, Piao JH, Xue X, Okumura K: Cell Death Differ 2006;13:730-737.

17 Lo'pez-Neblina F, Toledo-Pereyra LH: Phosphoregulation of signal transduction pathways in ischemia and reperfusion. J Surg Res 2006;134:292-299.

18 Lønborg JT: Targeting reperfusion injury in the era of primary percutaneous coronary intervention: hope or hype? Heart 2015;101:1612-1618.

19 Ballow M: Immunoglobulin therapy: methods of delivery. J Allergy Clin Immunol 2008;122:1038-1039.

20 Gelfand EW: Intravenous immune globulin in autoimmune and inflammatory diseases. N Engl J Med 2012;367:2015-2025.

-21 Mouthon L, Kaveri SV, Spalter SH, Lacroix-Desmazes S, Lefranc C, Desai R, Kazatchkine MD: Mechanisms of action of intravenous immune globulin in immune-mediated diseases. Clin Exp Immunol 1996;104 Suppl 1:3-9.

22 Schwab I, Nimmerjahn F: Intravenous immunoglobulin therapy: how does IgG modulate the immune system. Nat Rev Immunol 2013;13:176-189.

23 Giakoustidis D, Papageorgiou G, Kostopoulou E, Iliadis S, Giakoustidis A, Kontos N, Tsantilas D, Botsoglou N: High dose intravenous immunoglobulin g pretreatment: effect on lipid peroxidation and reperfusion injury to the liver. World J Surg 2003;27:1300-1305.

-24 Anderson J, Fleming SD, Rehrig S, Tsokos GC, Basta M, Shea-Donohue T: Intravenous immunoglobulin attenuates mesenteric ischemia-reperfusion injury. Clin Immunol 2005;114:137-146.

25 Lok KZ, Basta M, Manzanero S, Arumugam TV: Intravenous immunoglobulin (IVIg) dampens neuronal tolllike receptor-mediated responses in ischemia. J Neuroinflammation 2015;15;12:73.

-26 Arumugam TV, Tang SC, Lathia JD, Cheng A, Mughal MR, Chigurupati S, Magnus T,Chan SL, Jo DG, Ouyang X, Fairlie DP, Granger DN, Vortmeyer A, Basta M, Mattson MP. Intravenous immunoglobulin (IVIG) protects the brain against experimentalstroke by preventing complement-mediated neuronal cell death: Intravenous immunoglobulin (IVIG) protects the brain against experimental stroke by preventing complementmediated neuronal cell death. Proc Natl Acad Sci U S A 2007;104:14104-14109.

-27 Widiapradja A, Vegh V, Lok KZ, Manzanero S, Thundyil J, Gelderblom M, Cheng YL, Pavlovski D, Tang SC, Jo DG, Magnus T, Chan SL, Sobey CG, Reutens D, Basta M, Mattson MP, Arumugam TV: Intravenous immunoglobulin protects neurons against amyloid beta-peptide toxicity and ischemic stroke by attenuating multiple cell death pathways. J Neurochem 2012;122:321-332.

28 Khalaf A, Babiker F: Discrepancy in calcium release from the sarcoplasmic reticulum and intracellular acidic stores for the protection of the heart against ischemia/reperfusion injury. J Physiol Biochem 2016;72:495-508.

-29 Hansen A, Kumar A, Wolf D, Frankenbergerova K, Filusch A, Gross ML, Mueller S, Katus H, Kuecherer $\mathrm{H}$ : Evaluation of cardioprotective effects of recombinant soluble P-selectin glycoprotein ligandimmunoglobulin in myocardial ischemia-reperfusion injury by real-time myocardial contrast echocardiography. J Am Coll Cardiol 2004;18;44:887-891.

-30 Ferrera R, Benhabbouche S, Bopassa JC, Li B, Ovize M: One hour reperfusion is enough to assess function and infarct size with TTC staining in Langendorff rat model. Cardiovasc Drugs Ther 2009;23:327-331.

-31 Babiker FA, Lips D, Meyer R, Delvaux E, Zandberg P, Janssen B, van Eys G, Grohé C, Doevendans PA: Estrogen receptor beta protects the murine heart against left ventricular hypertrophy. Arterioscler Thromb Vasc Biol 2006;26:1524-1530.

32 Jiang YQ, Chang GL, Wang Y, Zhang DY, Cao L, Liu J: Geniposide Prevents Hypoxia/Reoxygenation-Induced Apoptosis in H9c2 Cells: Improvement of Mitochondrial Dysfunction and Activation of GLP-1R and the PI3K/AKT Signaling Pathway. Cell Physiol Biochem 2016;39:407-421.

33 Chen C, Chen W, Nong Z, Ma Y, Qiu S, Wu G: Cardioprotective Effects of Combined Therapy with Hyperbaric Oxygen and Diltiazem Pretreatment on Myocardial Ischemia-Reperfusion Injury in Rats. Cell Physiol Biochem 2016;38:2015-2029.

-34 Jian J, Xuan F, Qin F, Huang R: The Antioxidant, Anti-Inflammatory and Anti-Apoptotic Activities of the Bauhinia Championii Flavone are Connected with Protection Against Myocardial Ischemia/Reperfusion Injury. Cell Physiol Biochem 2016;38:1365-1375.

-35 Zhang JY, Wu F, Gu XM, Jin ZX, Kong LH, Zhang Y, Zhou JJ, Gao F: The Blockade of Transmembrane $\mathrm{Cl}^{-}$ Flux Mitigates I/R-Induced Heart Injury via the Inhibition of Calpain Activity. Cell Physiol Biochem 2015;35:2121-2134. 


\section{Cellular Physiology Cell Physiol Biochem 2017;42:2295-2306 \begin{tabular}{ll|l} 
DOI: 10.1159/000480002 & $\begin{array}{l}\text { O 2017 The Author(s). Published by S. Karger AG, Basel } \\
\text { www.karger.com/cpb }\end{array}$ \\
and Biochemistry Publisned online: August 17, 2017 &
\end{tabular}}

-36 Freixa X, Bellera N, Ortiz-Pérez JT, Jiménez M, Paré C, Bosch X, De Caralt TM, Betriu A, Masotti M: Ischaemic postconditioning revisited: lack of effects on infarct size following primary percutaneous coronary intervention. Eur Heart J 2012;33:103-112.

-37 Hahn JY, Song YB, Kim EK, Yu CW, Bae JW, Chung WY, Choi SH, Choi JH, Bae JH, An KJ, Park JS, Oh JH, Kim SW, Hwang JY, Ryu JK, Park HS, Lim DS, Gwon HC: Ischemic postconditioning during primary percutaneous coronary intervention: the effects of postconditioning on myocardial reperfusion in patients with STsegment elevation myocardial infarction (POST) randomized trial. Circulation 2013;128:1889-1896.

-38 Limalanathan S, Andersen GØ, Kløw NE, Abdelnoor M, Hoffmann P, Eritsland J: Effect of ischemic postconditioning on infarct size in patients with ST-elevation myocardial infarction treated by primary PCI results of the POSTEMI (POstconditioning in ST-Elevation Myocardial Infarction) randomized trial. J Am Heart Assoc 2014;3:e000679.

-39 Murry CE, Jennings RB, Reimer KA: Preconditioning with ischemia: a delay of lethal cell injury in ischemic myocardium. Circulation 1986;74:1124-1136.

40 Juggi JS, Hoteit LJ, Babiker FA, Joseph S, Mustafa AS: Protective role of normothermic, hyperthermic and estrogen preconditioning and pretreatment on tumour necrosis factor-alpha-induced damage. Exp Clin Cardiol 2011;16:e5-e10.

41 Vanagt WY, Cornelussen RN, Poulina QP, Blaauw E, Vernooy K, Cleutjens JP, van Bilsen M, Delhaas T, Prinzen FW: Pacing-induced dys-synchrony preconditions rabbit myocardium against ischemia/reperfusion injury. Circulation 2006;114:1-264-1-269.

-42 Zhao ZQ, Corvera JS, Halkos ME, Kerendi F, Wang NP, Guyton RA, Vinten-Johansen J: Inhibition of myocardial injury by ischemic postconditioning during reperfusion: comparison with ischemic preconditioning. Am J Physiol Heart Circ Physiol 2003;285:H579-588.

-43 Gullestad L, Orn S, Dickstein K, Eek C, Edvardsen T, Aakhus S, Askevold ET, Michelsen A, Bendz B, Skårdal R, Smith HJ, Yndestad A, Ueland T, Aukrust P: Intravenous immunoglobulin does not reduce left ventricular remodeling in patients with myocardial dysfunction during hospitalization after acute myocardial infarction. Int J Cardiol 2013;168:212-218.

44 Fann DY, Lee SY, Manzanero S, Tang SC, Gelderblom M, Chunduri P, Bernreuther C, Glatzel M, Cheng YL, Thundyil J, Widiapradja A, Lok KZ, Foo SL, Wang YC, Li YI, Drummond GR, Basta M, Magnus T, Jo DG, Mattson MP, Sobey CG, Arumugam TV: Intravenous immunoglobulin suppresses NLRP1 and NLRP3 inflammasome-mediated neuronal death in ischemic stroke. Cell Death Dis 2013;4:e790.

45 Comparin C, Hans Filho G, Takita LC, Costa Nde C, Nascimento RA, Nanni Lde O: Treatment of toxic epidermal necrolysis with intravenous immunoglobulin: a series of three cases. An Bras Dermatol 2012;87:477-481.

46 Winkler J, Kroiss S, Rand ML, Azzouzi I, Annie Bang KW, Speer O, Schmugge M: Platelet apoptosis in paediatric immune thrombocytopenia is ameliorated by intravenous immunoglobulin. Br J Haematol 2012;156:508-515.

47 Séité JF, Cornec D, Renaudineau Y, Youinou P, Mageed RA, Hillion S: IVIg modulates BCR signaling through CD22 and promotes apoptosis in mature human B lymphocytes. Blood 2010;116:1698-1704.

48 Babiker FA, van Golde J, Vanagt WY, Prinzen FW: Pacing postconditioning: impact of pacing algorithm, gender, and diabetes on its myocardial protective effects. J Cardiovasc Transl Res 2012;5:727-734.

49 Walters AM, Porter GA Jr, Brookes PS: Mitochondria as a drug target in ischemic heart disease and cardiomyopathy. Circ Res 2012;111:1222-1236.

-50 Babiker FA, Hoteit LJ, Joseph S, Mustafa AS, Juggi JS: The role of 17-beta estradiol in ischemic preconditioning protection of the heart. Exp Clin Cardiol2012;17:95-100.

-51 Xiong J, Yuan YJ, Xue FS, Wang Q Cheng Y, Li RP, Liao X, Liu JH, Xiong J, Yuan YJ, Xue FS, Wang Q Cheng Y, Li RP, Liao X, Liu JH: Postconditioning with alpha7nAChR agonist attenuates systemic inflammatory response to myocardial ischemia-reperfusion injury in rats. Inflammation 2012;35:1357-1364.

52 Aukrust P, Frøland SS, Liabakk NB, Müller F, Nordøy I, Haug C, Espevik T: Release of cytokines, soluble cytokine receptors, and interleukin-1 receptor antagonist after intravenous immunoglobulin administration in vivo. Blood 1994;84:2136-2143.

-53 Ibáñez C, Suñé P, Fierro A, Rodríguez S, López M, Alvarez A, De Gracia J: Modulating effects of intravenous immunoglobulins on serum cytokine levels in patients with primary hypogammaglobulinemia. BioDrugs 2005;19:59-65.

54 Bagdasarian A, Tonetta S, Harel W, Mamidi R, Uemura Y: IVIG adverse reactions: potential role of cytokines and vasoactive substances. Vox Sang 1998;74:74-82. 